poor and the publication could have been improved greatly by arrangement of the articles into sections under headings. In summary, a useful review of the chemistry and structure-activity relations of several groups of CNS drugs, but not a cohesive or representative account of research in this area.

L. L. IVERSen

\section{BOOK OF BREWING}

\section{Principles of Industrial Microbiology}

By Alan Rhodes and Derek L. Fletcher. (The Commonwealth and International Library of Science, Technology, Engineering and Liberal Studies; Microbiology Division.) Pp. xviii +320 . (London and New York: Pergamon Press, Ltd., 1966.) 35s. net.

THIs book is an account of the knowledge of everyday importance to the microbiologist working in the field of industrial fermentation, which is being rapidly transformed from a mysterious art to a science-based industry - beer will soon be produced according to a mathematical equation instead of the reaction of the chief brewer to a glance and a sniff at the liquor in the vat. Rather than treat each fermentation as a separate entity, which has been the usual approach to the subject, the authors have attempted to distinguish and discuss the common underlying principles. Such a unified approach to fermentation technology is clearly necessary.

This study appropriately covers the physical or engineering, biological and chemical principles. The account of the design of a fermentation unit includes the culture vessels for fermentations and equipment for recovery of products. The design of culture vessels, considering its basic importance to the whole of the technology, is dealt with superficially, but this could be a true reflexion of the industry's approach at the moment to this important subject. We learn that fermenters are designed by rule of thumb for the most part. Sterilization is also dealt with in a most elementary manner, for example, the theory of sterilization by filtration is not discussed or referred to. In the chapter on aeration and agitation, the discussion of agitation is full and stimulating. In contrast, aeration, despite the mass of information about it, is cursorily dismissed.

The technical importance of genetics and screening of organisms for useful products are effectively reviewed. The chapter on nutrition is an interesting account of media, but largely avoids the principles. The chapters on the biochemistry of fermentations provide a valuable advanced account of the latest concepts in a wide range of biosyntheses of industrial importance and their relation to basic metabolic pathways. Antibioties, steroids, vitamins, vaccine production, food fermentation and effluent disposal are all mentioned. Important details of modern fermentation processes for the production of streptomycin, griseofulvin and tetracyclines can be found here. The main criticism of the book is that the more physical and kinetic aspects of fermentation have not been dealt with as fully as the biochemistry, although the former are of crucial importance.

The style of the writing is pleasingly concise. One is irritated by the printing of Fig. 9.3, which cannot be read without a magnifying glass, and in chapter 7 by use of the same symbol $W$ for both work and width. The book is suitable for degree and postgraduate courses as well as industrial microbiologists, but the standard is uneven; for example, it is gratuitous to give the formula for converting ${ }^{\circ} \mathrm{C}$ to ${ }^{\circ} \mathrm{F}$ and even metres to centimetres.

On the whole, the authors have succeeded in their task of formulating the scientific basis of fermentation. It is a timely contribution to microbiological studies which are now the basis of a large part of the chemical and food industries.

S. J. PirT

\section{CALCULATING REACTIONS}

\section{Chemical Relaxation}

An Introduction to Theory and Application of Stepwise Perturbation. By George H. Czerlinski. Pp. xiii +314. (London: Edward Arnold (Publishers), Ltd.; New York: Marcel Dekker, Inc., 1966.) 120s. net.

Measurement of the rate constants of fast reactions in solution has for a long time exercised the minds of chemical kineticists. Further zest has been added to this from a biochemical and biophysical point of view. Earlier techniques based on stationary state methods are limited to relatively few special cases. In recent years relaxation techniques have increased in importance, the best known being flash photolysis and more recently electron pulse radiolysis. In the wide field of thermal reactions the methods developed by Eigen and de Maeyer have made it possible to investigate a large number of reactions.

We have been promised a monograph by Professor Eigen himself, but as yet there only exists his excellent but rather short article with de Maeyer in Techniques of Organic Chemistry (Volume 8, (2) ; 1963). We are therefore indebted to Dr. Czerlinski, one of Eigen's early collaborators, for producing an introductory treatment of this important subject. The monograph deals rather broadly with the elementary theoretical background, and with the techniques of different types of equilibrium displacements, such as temperature jump, field jump, pressure jump, concentration jump as well as rapid flow with temperature jump. The treatment is somewhat uneven with regard to detail and the book is something between a monograph and a text-book; there are a number of problems at the end of each chapter which are suitable for postgraduate students.

The publication of this book will be welcome by all who are interested in this field. It will certainly be very useful until a comprehensive monograph comes from Professor Eigen himself. It is well produced with a number of good illustrations. The price seems rather high for a slim volume of this type. J. J. WEISS

\section{FINDING INFORMATION}

\section{Textbook on Mechanized Information Retrieval}

By Allen Kent. Second edition. (Library Science and Documentation: a Series of Texts and Monographs, Vol. 3.) Pp. $x x+371$. (New York and London: Interscience Publishers, a Division of John Wiley and Sons, 1966.) $85 s$.

Annual Review of Information Science and Technology Vol. 1. Edited by Carlos A. Cuadra. (American Documentation Institute.) Pp. ix +389 . (New York and London: Interscience Publishers, a Division of John Wiley and Sons, 1966.) $100 s$.

WHILE the use of computers for routine library operations can now be considered an accepted fact, it is still a matter for doubt as to how far mechanization will be able to go in the more specialized field of information retrieval. As Professor Kent says in the second editicn of his book, "the field is still in a state of flux". It is difficult to write a good text-book in these conditions, and many changes have been made as a result of the experience gained in using the first edition. The volume still remains an excellent introduction to the subject, both for the student and for those faced with the practical problem of developing a mechanized system.

The Annual Review of Information Science and Technology takes over from the previous book by attempting to cover, under thirteen separate headings, the research work now being undertaken in the field of information science. It is symptomatic of this activity that more than 95 per cent of the references are to work undertaken in 